\title{
Evaluation of System Modelling Techniques for Waste Identification in Lean Healthcare Applications
}

This article was published in the following Dove Press journal:

Risk Management and Healthcare Policy

\author{
Maitha Alkaabi' \\ Mecit Can Emre Simsekler (D) \\ Raja Jayaraman (iD ' \\ Abdulqader Al Kaf' \\ Hussam Ghalib ${ }^{2}$ \\ Dima Quraini ${ }^{2}$ \\ Samer Ellahham (iD ${ }^{2}$ \\ E Murat Tuzcu ${ }^{2}$ \\ Kudret Demirli ${ }^{3}$ \\ 'Department of Industrial and Systems \\ Engineering, Khalifa University of Science \\ and Technology, Abu Dhabi, United Arab \\ Emirates; ${ }^{2}$ Heart and Vascular Institute, \\ Cleveland Clinic Abu Dhabi, Abu Dhabi, \\ United Arab Emirates; ${ }^{3}$ Department of \\ Mechanical, Industrial and Aerospace \\ Engineering, Concordia University, \\ Montreal, Canada
}

Purpose: Waste identification plays a vital role in lean healthcare applications. While the value stream map (VSM) is among the most commonly used tools for waste identification, it may be limited to visualize the behaviour of dynamic and complex healthcare systems. To address this limitation, system modelling techniques (SMTs) can be used to provide a comprehensive picture of various system-wide wastes. However, there is a lack of evidence in the current literature about the potential contribution of SMTs for waste identification in healthcare processes.

Methods: This study evaluates the usability and utility of six types of SMTs along with the VSM. For the evaluation, interview-based questionnaires were conducted with twelve stakeholders from the outpatient clinic at the Heart and Vascular Institute at Cleveland Clinic Abu Dhabi.

Results: VSM was found to be the most useful diagram in waste identification in general. However, some SMTs that represent the system behaviour outperformed the VSM in identifying particular waste types, e.g., communication diagram in identifying overprocessing waste and flow diagram in identifying transportation waste.

Conclusion: As behavioural SMTs and VSM have unique strengths in identifying particular waste types, the use of multiple diagrams is recommended for a comprehensive waste identification in lean. However, limited resources and time, as well as limited experience of stakeholders with SMTs, may still present obstacles for their potential contribution in lean healthcare applications.

Keywords: lean healthcare, value stream map, system modelling techniques, waste identification, kaizen, system approaches, healthcare operations

\section{Introduction}

Lean is a reengineering philosophy ${ }^{1}$ that aims to improve process and system efficiency by reducing non-value-added activities and wastes. ${ }^{2}$ Lean has gained significant attention in the healthcare industry to develop safe, efficient and wastefree operational processes. ${ }^{3-5}$ Recent studies reported positive results in various healthcare applications, such as reducing patient waiting time and length of hospital stay, ${ }^{6,7}$ improved resource utilization and staff satisfaction. ${ }^{8,9}$

An important aspect of lean is the waste identification to reduce non-valueadded activities and provide standardized solutions for better performance and operational excellence. $^{1,10}$ Lean aims to identify the following eight types of waste: transportation, inventory, motion, waiting, overproduction, over-processing, defect and human potential. ${ }^{11,12}$ Earlier studies showed that stakeholder engagement is imperative in the waste identification efforts in lean. ${ }^{13}$ Therefore, visual
Simsekler

Department of Industrial and Systems Engineering, Khalifa University of Science and Technology, P.O. Box 127788, Abu

Dhabi, United Arab Emirates

Tel +97125018410

Fax +97I 24472442

Email emre.simsekler@ku.ac.ae 
tools, such as value stream map (VSM), have been used to help stakeholders understand the overall system and identify wastes.

The VSM helps identify value-added and non-valueadded activities in producing specific outputs for users by describing the "current state" of operations. ${ }^{14}$ Earlier research demonstrates positive results with the use of VSM. ${ }^{15-18}$ Further, studies showed that the VSM catalyse staff engagement and transformational improvement. ${ }^{14,19}$ Despite these benefits, the VSM may not always represent important support functions and system attributes in the patient flow. Therefore, the VSM may not help identify all types of wastes in healthcare effectively. ${ }^{20}$ Further, it may not well represent the system behaviour, e.g., communication between stakeholders and other support functions. Due to these limitations, recent studies investigated possible alterations to the VSM to exploit its use in waste identification. ${ }^{20}$ In parallel with this, various system modelling techniques (SMTs) can also facilitate visual representation of the system structure and behaviour.

SMTs (also known as process maps, system diagrams, and system modelling approaches) are visual tools that provide a diagrammatic description of processes and systems. While a wide range of SMTs have been used in other safety-critical industries, such as aviation, they have been underused in the healthcare field. ${ }^{21-23}$ Earlier studies showed the contribution of SMTs in identifying potential safety issues in complex healthcare systems. ${ }^{22,24,25}$

A comprehensive study on the usability of SMTs was conducted by Clarkson and colleagues. ${ }^{26}$ Considering the suitability of SMTs in capturing different system attributes, they shortlisted six different diagram types that provide fundamental diagrammatic representation on the system structure and behaviour in healthcare settings. Task diagrams, information diagrams and organizational diagrams are used to describe the hierarchy of operations, information and people and their roles within the organization, respectively. Communication diagrams represent the flow of material and/or information between people and process. While flow diagrams represent activities taking place in parallel or sequence, system diagrams are used to show data transfer between activities. While the first three diagrams are structural ones describing the system architecture and defining its boundaries, the last three diagrams are behavioural, expanding the system description and presenting the communication and flow of information and people within the process. ${ }^{27}$
To comprehensively describe the system structure and behaviour, earlier studies showed the potential contribution of SMTs in representing the patient journey in a visual way $^{28,29}$ and guiding caregivers in problem identification and mitigation efforts. ${ }^{30}$ The strength of SMTs has been recognized in understanding existing systems before implementing improvement suggestions ${ }^{31}$ and identifying patient safety risks. ${ }^{28,30,32,33}$ Similarly, visualization of the system through different SMTs can potentially strengthen the waste identification process in lean and help users in the decision-making process. ${ }^{31}$ It is therefore imperative to evaluate the usability and utility of each SMT to better understand its potential role in waste identification for the healthcare process. It is also essential to identify what specific types of waste can be identified using a particular type of SMT compared to VSM.

\section{Methods}

This study aims to evaluate the usability and utility of SMTs in waste identification. To achieve this, this research considered six different types of SMTs that were comprehensively shortlisted based on their practicality and suitability in capturing different system attributes. ${ }^{26}$ Besides these SMTs, the VSM was evaluated to compare its usefulness against the SMTs in the same context. As outputs, eight types of wastes that are articulated in lean applications are included. The SMTs, along with the VSM, are evaluated at the outpatient clinic of the Heart and Vascular Institute (HVI) at Cleveland Clinic Abu Dhabi (CCAD), which is a 364-bed multi-specialty tertiary hospital located in Abu Dhabi, UAE.

Two data sets were obtained throughout the study. The first data set was obtained to fully understand the patient journey in the chosen clinic and represent them in the shortlisted SMTs and VSM. The patient journey in the clinic is segmented into five stations: registration, nurse assessment, physician examination, testing and check-out process. Based on observations, informal discussions with stakeholders and shadowing, the general flow of patients, tasks and communication were presented in relevant SMTs via Microsoft Visio (see Appendix). At this stage, the suitability of the SMTs was also shared with the clinical operation manager to validate that they represent the actual practice in the clinic.

The second data set was obtained to evaluate the usability and utility of SMTs in waste identification through interview-based questionnaires with stakeholders from the clinic who voluntarily participated in this study. 
This method was mainly adopted with the intent to capture both qualitative and quantitative feedback from participants. Further, this particular method was expected to capture the rationale behind participants' comments and guide them better if there is any ambiguity in SMTs.

In total, twelve participants volunteered to represent all types of stakeholders or care providers in the clinic: two patient access representatives (PARs), two nurses, two technologists, two managers, three physicians, and one health unit coordinator (HUC). The questionnaire consists of three sections. In the first section, participants were asked about their background, such as their current position, working period in healthcare and familiarity with the system modelled (HVI system) and SMTs.

In the second section, three aspects of the usability and utility of SMTs and VSM were asked as follows:

- This system model is easily understandable with the instruction given (usability)

- This system model is helpful in better understanding and communicating the system's operations (utility in system understanding and communication)

- This system model is helpful in identifying waste within the system (utility in waste identification)

The questions were presented to the participants in a tabular form together with the seven diagrams (organizational diagram, information diagram, task diagram, flow diagram, communication diagram, system diagram, and value stream map). Participants were then asked to choose the degree of agreement for each diagram. Prior to the evaluation, participants went through a ten-minute briefing about the nature of the SMT by the first author. Following the training. It involved the definition of waste types with examples on each and a brief explanation about the SMTs. Then, participants were guided through the diagrams one by one.

In the third section, participants were asked to state their degree of agreement with each SMT's strength in identifying particular types of waste.

The rankings were numerically assigned for further analysis following the data collection. Five-point-Likert scales (strongly disagree: 1 - strongly agree: 5) were used to record the responses. The participants were asked to select the one option that closely represents their opinion regarding their experience with each SMT. Due to the small sample size as a nature of this study, a test of significance for normality was limited; therefore, descriptive statistics were obtained to summarize the evaluation results.

\section{Results}

Twelve participants from the clinic volunteered to participate in this study. Table 1 presents their job titles, their previous experience in the clinic and in using SMTs: The majority had self-reported limited experience with SMTs.

In the second section of the questionnaire, the usability and utility of the SMTs were captured. The summary statistics of the evaluation can be found in Table 2 .

Table I Participants in SMT Evaluation

\begin{tabular}{|c|c|c|c|c|}
\hline No. & Job Title & $\begin{array}{l}\text { Experience in } \mathrm{HC} \\
\text { (years) }\end{array}$ & $\begin{array}{l}\text { Familiarity with HVI } \\
\text { System }\end{array}$ & Experience and Purpose of in Using SMTs \\
\hline 1 & Physician & 25 & Very familiar & On a regular basis - Quality related projects \\
\hline 2 & Physician & 14 & A little & None \\
\hline 3 & Physician & 10 & Medium & A couple of times - problem-solving projects \\
\hline 4 & Department administrator & 9 & A little & $\begin{array}{l}\text { A couple of times - workflows and employment } \\
\text { purposes }\end{array}$ \\
\hline 5 & Department administrator & 10 & Very familiar & Sometimes - engineering school \\
\hline 6 & Practical nurse & 8.5 & Medium & None \\
\hline 7 & Practical nurse & 7 & Very familiar & Sometimes - Clinical training purposes \\
\hline 8 & Nurse and Stress test Technologist & 10 & Very familiar & None \\
\hline 9 & EKG technologist & 24 & Very familiar & Sometimes - Clinical training purposes \\
\hline 10 & Patient access registration (PAR) & 8 & Very familiar & $\begin{array}{l}\text { Sometimes - Clinical training purposes and } \\
\text { during university study }\end{array}$ \\
\hline II & Patient access registration (PAR) & 1.5 & Very familiar & $\begin{array}{l}\text { Sometimes - Clinical training purposes and } \\
\text { during university study }\end{array}$ \\
\hline 12 & Health unit coordinator (HUC) & II & Very familiar & A couple of times - Clinical training purposes \\
\hline
\end{tabular}


Table 2 Summary Statistics of SMT Evaluation $(n=12)$

\begin{tabular}{|c|c|c|c|c|c|c|c|c|c|c|c|c|c|}
\hline \multirow{2}{*}{$\begin{array}{l}\text { Statement on } \\
\text { Usefulness in Waste } \\
\text { Identification }\end{array}$} & \multicolumn{4}{|c|}{ Organisational Diagram } & \multicolumn{4}{|c|}{ Information Diagram } & \multicolumn{4}{|c|}{ Task Diagram } & \multirow{2}{*}{$\begin{array}{l}\text { Flow } \\
\text { Mean }\end{array}$} \\
\hline & Mean & $\begin{array}{l}\text { Standard } \\
\text { Deviation }\end{array}$ & Median & $\begin{array}{l}\text { Inter } \\
\text { Quartile } \\
\text { Range, } \\
\text { IQR }\end{array}$ & Mean & $\begin{array}{l}\text { Standard } \\
\text { Deviation }\end{array}$ & Median & $\begin{array}{l}\text { Inter } \\
\text { Quartile } \\
\text { Range, } \\
\text { IQR }\end{array}$ & Mean & $\begin{array}{l}\text { Standard } \\
\text { Deviation }\end{array}$ & Median & $\begin{array}{l}\text { Inter } \\
\text { Quartile } \\
\text { Range, } \\
\text { IQR }\end{array}$ & \\
\hline Ease of understanding & 4.6 & 0.7 & 4.0 & 1.0 & 4.2 & 0.8 & 4.0 & 1.3 & 4.5 & 0.5 & 4.5 & 1.0 & 4.5 \\
\hline $\begin{array}{l}\text { Understanding and } \\
\text { communicating the } \\
\text { system operations }\end{array}$ & 4.3 & 1.0 & 4.5 & 1 & 4.2 & 0.7 & 4.0 & 1 & 4.3 & 0.5 & 4.0 & 1 & 4.3 \\
\hline $\begin{array}{l}\text { General usefulness in } \\
\text { waste identification }\end{array}$ & 3.6 & 1.4 & 4.0 & 1.25 & 4.2 & 0.7 & 4.0 & 1 & 4.3 & 0.7 & 4.0 & 1 & 4.3 \\
\hline $\begin{array}{l}\text { Particular usefulness in } \\
\text { identifying } \\
\text { overproduction waste }\end{array}$ & 2.8 & 1.5 & 2.0 & 2.25 & 3.2 & 1.6 & 4.0 & 2.5 & 3.7 & 1.3 & 4.0 & 0 & 4.1 \\
\hline $\begin{array}{l}\text { Particular usefulness in } \\
\text { identifying inventory } \\
\text { waste }\end{array}$ & 2.3 & 1.5 & 2.0 & 3 & 2.4 & 1.2 & 2.5 & 2.25 & 3.0 & 1.5 & 3.5 & 2.25 & 3.3 \\
\hline $\begin{array}{l}\text { Particular usefulness in } \\
\text { identifying defect waste }\end{array}$ & 2.2 & 1.3 & 2.0 & 2 & 3.2 & 1.5 & 4.0 & 2.25 & 2.7 & 1.4 & 2.5 & 2.25 & 3.2 \\
\hline $\begin{array}{l}\text { Particular usefulness in } \\
\text { identifying over- } \\
\text { processing waste }\end{array}$ & 2.2 & 1.5 & 1.5 & 2.25 & 3.8 & 1.0 & 4.0 & 0 & 3.6 & 1.1 & 4.0 & 0.25 & 4.3 \\
\hline $\begin{array}{l}\text { Particular usefulness in } \\
\text { identifying motion waste }\end{array}$ & 2.4 & 1.4 & 2.0 & 3 & 2.6 & 1.5 & 2.0 & 3 & 3.5 & 1.2 & 4.0 & 0.25 & 4.3 \\
\hline $\begin{array}{l}\text { Particular usefulness in } \\
\text { identifying } \\
\text { transportation waste }\end{array}$ & 1.8 & 1.2 & 1.0 & 1.25 & 2.8 & 1.3 & 3.5 & 2.25 & 3.6 & 1.4 & 4.0 & 2.25 & 4.2 \\
\hline $\begin{array}{l}\text { Particular usefulness in } \\
\text { identifying waiting waste }\end{array}$ & 1.9 & 1.2 & 1.5 & 1.25 & 2.6 & 1.5 & 2.0 & 3 & 3.6 & 1.2 & 4.0 & 1.25 & 4.2 \\
\hline $\begin{array}{l}\text { Particular usefulness in } \\
\text { identifying human } \\
\text { potential waste }\end{array}$ & 3.0 & 1.3 & 3.0 & 2 & 2.4 & 1.3 & 2.0 & 3 & 3.6 & 1.1 & 4.0 & 1 & 3.8 \\
\hline
\end{tabular}

Figure 1 shows the average grade for each question collected from the participants.

As shown in Figure 1, the SMTs with the structural link (organizational diagram, information diagram, and task diagram) were rated more easily understandable than the ones with the behavioural link (flow diagram, communication diagram, and system diagram). On average, the organizational diagram was the easiest model to understand. Participants' comments during the interview also reflected their ratings. For instance, they pointed out that the structural diagrams are simple and easy to understand. The task diagram was expressed as a useful diagram in reflecting the process details. The flow diagram was described as complicated because of the sequence of the tasks, mainly if multiple procedures occur in parallel. The system diagram was also found to be complicated as it was observed to be too detailed by the participants. Moving to the communication diagram, participants, in general, found it difficult to follow as it showed patient flow and information flow simultaneously. The VSM was also found to be slightly similar to the flow diagram but with less complexity and involves additional information, such as processing time and capacity in each step of the patient journey.

Based on the participants' feedback during the interview, it was noticed that their previous experience with the diagrams also influenced their responses with ease of understanding the diagrams. For instance, three participants had no experience with the SMTs, while experienced participants were able to make a clear connection between the content of the diagrams and their work area. Also, experienced participants were able to relate the capacity and cycle times given in the value stream map with their key performance indicators (KPIs), demonstrating the effectiveness of clinical targets in achieving its overall objectives.

For the second question in section two in the questionnaire, most participants found the diagrams helpful in understanding and communicating the system operations with little disagreement. Most participants agreed that the VSM is particularly useful in explaining the system operations. The participants also expressed that the flow 


\begin{tabular}{|c|c|c|c|c|c|c|c|c|c|c|c|c|c|c|}
\hline \multicolumn{3}{|l|}{ Diagram } & \multicolumn{4}{|c|}{ Communication Diagram } & \multicolumn{4}{|c|}{ System Diagram } & \multicolumn{4}{|c|}{ Value Stream Map } \\
\hline $\begin{array}{l}\text { Standard } \\
\text { Deviation }\end{array}$ & Median & $\begin{array}{l}\text { Inter } \\
\text { Quartile } \\
\text { Range, } \\
\text { IQR }\end{array}$ & Mean & $\begin{array}{l}\text { Standard } \\
\text { Deviation }\end{array}$ & Median & $\begin{array}{l}\text { Inter } \\
\text { Quartile } \\
\text { Range, } \\
\text { IQR }\end{array}$ & Mean & $\begin{array}{l}\text { Standard } \\
\text { Deviation }\end{array}$ & Median & $\begin{array}{l}\text { Inter } \\
\text { Quartile } \\
\text { Range, } \\
\text { IQR }\end{array}$ & Mean & $\begin{array}{l}\text { Standard } \\
\text { Deviation }\end{array}$ & Median & $\begin{array}{l}\text { Inter } \\
\text { Quartile } \\
\text { Range, } \\
\text { IQR }\end{array}$ \\
\hline 0.9 & 5.0 & 1.0 & 4.3 & 1.2 & 5.0 & 1.0 & 4.1 & 1.4 & 5.0 & 1.3 & 4.3 & 0.7 & 4 & 1 \\
\hline 0.7 & 4.0 & I & 4.4 & 0.7 & 4.5 & 1 & 4.3 & 0.9 & 4.5 & I & 4.6 & 0.5 & 5.0 & I \\
\hline 0.9 & 4.0 & 1 & 4.1 & 0.9 & 4.0 & 1 & 4.3 & 1.0 & 4.5 & 1 & 4.4 & 0.7 & 4.5 & 1 \\
\hline 0.9 & 4.0 & 1 & 3.6 & 1.4 & 4.0 & 2.25 & 3.7 & 1.2 & 4.0 & 1.25 & 4.2 & 0.8 & 4.0 & 1 \\
\hline 1.5 & 3.5 & 3 & 3.7 & 1.2 & 4.0 & 1.25 & 3.3 & 1.2 & 4.0 & 1.25 & 4.1 & 1.0 & 4.0 & 1.25 \\
\hline 1.6 & 3.0 & 3 & 3.7 & 1.3 & 4.0 & 2 & 3.7 & 1.2 & 4.0 & 1.25 & 3.8 & 1.3 & 4.0 & 2 \\
\hline I.I & 5.0 & 1.25 & 4.3 & 0.7 & 4.0 & 1 & 3.7 & 1.2 & 4.0 & 2.25 & 4.2 & 1.2 & 4.5 & 1 \\
\hline 0.9 & 4.5 & 1 & 4.1 & I.I & 4.0 & 1 & 3.8 & 1.3 & 4.0 & 1.25 & 4.4 & 0.8 & 5.0 & 1 \\
\hline 1.1 & 4.5 & 1 & 3.8 & 1.2 & 4.0 & 0.5 & 3.7 & 1.4 & 4.0 & 2.25 & 4.2 & 0.8 & 4.0 & 1.25 \\
\hline 1.2 & 5.0 & 1.25 & 4.0 & 1.0 & 4.0 & 1.25 & 3.8 & 1.3 & 4.0 & 2 & 4.7 & 0.7 & 5.0 & 0.25 \\
\hline 1.2 & 4.0 & 0.5 & 3.9 & 1.2 & 4.0 & 1.25 & 4.1 & 0.8 & 4.0 & 0.25 & 4.3 & 0.7 & 4.0 & 1 \\
\hline
\end{tabular}

diagram, communication diagram, and system diagram represent different system functions but not easy to track due to their complex nature. The organizational and information diagram had a lower agreement in their utility in communicating the system, as they were not found effective diagrams in reflecting the operational process.

For the third question in section two in the questionnaire, participants were asked to grade the usefulness of SMTs in identifying the wastes in the processes. The participants found all the diagrams useful for waste identification; however, the organizational diagram received the lowest ranking. Participants agreed that the most helpful diagram in waste identification is the VSM, followed by the system diagram and task diagram.

The third section of the questionnaire was intended to identify particular types of wastes using different SMTs. Figure 2 presents the results for this specific question.

The VSM was found as the most useful diagram type in identifying overproduction, inventory, motion, waiting and human potential waste types with the highest average scores; 4.2, 4.1, 4.4, 4.7 and 4.3, respectively. For waiting waste in particular, some participants mentioned that the VSM outperforms as cycle time is presented for each task. They highlighted that delays could also be identified via VSM with their possible contribution to the system performance. It was found that SMTs were not very helpful in identifying the system's defects as the highest average for any type of SMT was scored below 4.0. For over-processing waste type, flow diagram and communication diagram were found as the most useful diagrams with an average score of 4.3. The participants also pointed out that some tasks that require additional communication and interaction between stakeholders may be performed in addition to regular tasks in real practice. Therefore, they highlighted the usefulness of the flow diagram and the communication diagram in ascertaining their impact in the given system. In identifying transportation waste, both flow diagram and VSM were found equally useful with an average score of 4.2 . 


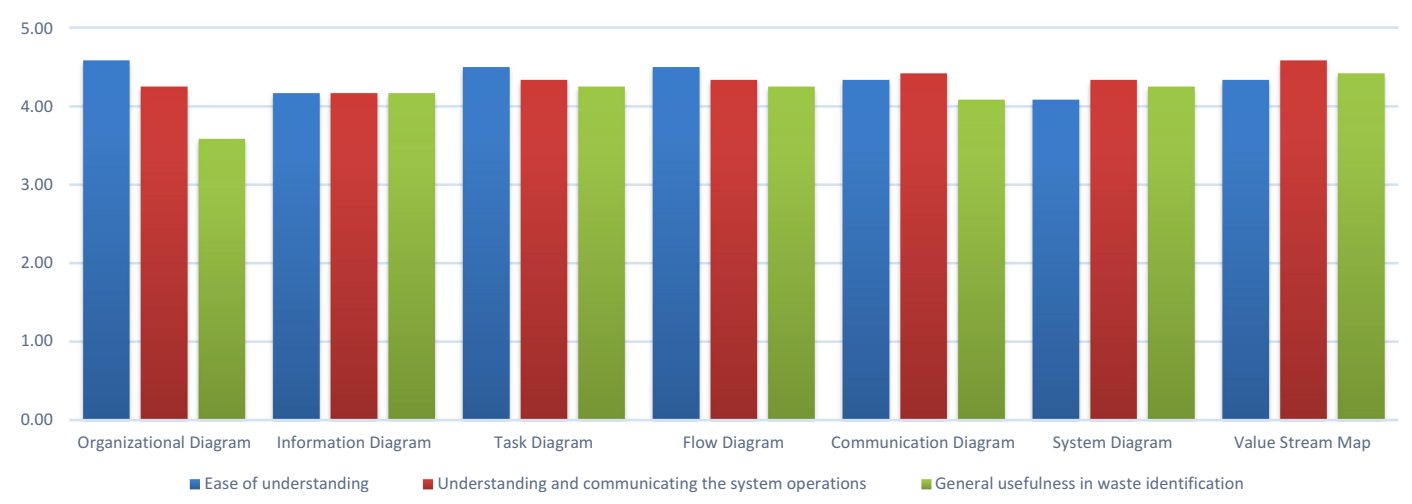

Figure I The general usability and utility of SMTs in waste identification.

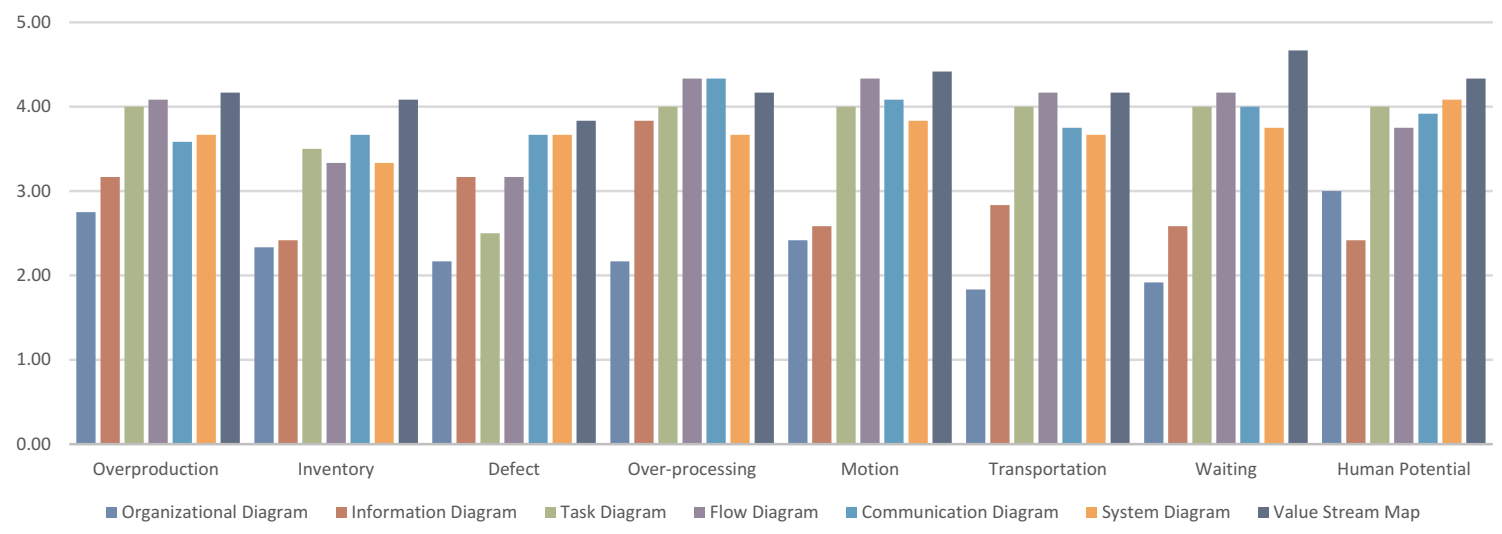

Figure 2 Usefulness of SMTs in Identifying Particular Waste Type.

\section{Discussion}

This study provides valuable insight into the usability and utility of SMTs in identifying systemic wastes that are well articulated in lean. The results showed that the diagrams with structural links, in general, are easier to understand compared to the ones with the behavioural links. Regarding usability and utility in waste identification, behavioural diagrams were found to be more useful, although the communication diagram scored lower than information and task diagrams. Further, structural diagrams were not very useful in identifying particular types of wastes.

Based on the average rates given in ranking, the VSM was found as the most useful diagram in waste identification. This is consistent with the previous studies, ${ }^{14,20}$ showing that the VSM is a powerful waste identification tool. However, this study also showed that some SMTs, such as flow diagram and communication diagram, are more powerful than VSM in identifying particular waiting waste. However, it can be concluded that using multiple diagrams are more helpful to identify a comprehensive list of wastes during lean exercises, such as kaizen meetings. Even though SMTs have the potential to generate a clear description of the system from different perspectives, limited resources and time pressures may prevent the number of SMTs from being built and utilized for lean applications. To prioritize the use of diagrams for waste identification, the results of this study can be valuable. Table 3 shows the suitability of SMTs in identifying different types of wastes. Based on this table, a particular kind of SMT can be prioritized for waste identification efforts in lean.

During the interviews, it was validated that the participants' job types are related to the kinds of waste that can be recognized and identified. For instance, department administrators focused on over-processing issues since it is related to the nature of their work, such as monitoring capacity, cost, and utilization. In contrast, others were more interested in wastes that influence their day to day tasks. Further, the participants' background and experience in SMTs influenced their feedback and responses. Their 
Table 3 SMTs and Waste Types

\begin{tabular}{|c|c|c|c|c|c|c|c|}
\hline $\begin{array}{l}\text { SMT Type } \\
\text { Waste Type }\end{array}$ & $\begin{array}{l}\text { Organizational } \\
\text { Diagram }\end{array}$ & $\begin{array}{l}\text { Information } \\
\text { Diagram }\end{array}$ & $\begin{array}{l}\text { Task } \\
\text { Diagram }\end{array}$ & $\begin{array}{l}\text { Flow } \\
\text { Diagram }\end{array}$ & $\begin{array}{l}\text { Communication } \\
\text { Diagram }\end{array}$ & $\begin{array}{l}\text { System } \\
\text { Diagram }\end{array}$ & $\begin{array}{l}\text { Value } \\
\text { Stream Map }\end{array}$ \\
\hline $\begin{array}{l}\text { Overproduction } \\
\text { Inventory } \\
\text { Defect } \\
\text { Over-processing } \\
\text { Motion } \\
\text { Transportation } \\
\text { Waiting } \\
\text { Human Potential }\end{array}$ & & & & $\begin{array}{l}\checkmark \\
\\
\checkmark \\
\checkmark \\
\checkmark \\
\checkmark\end{array}$ & $\begin{array}{l} \\
\checkmark \\
\checkmark \\
\checkmark\end{array}$ & $\checkmark$ & $\begin{array}{l}\checkmark \\
\checkmark \\
\checkmark \\
\checkmark \\
\checkmark \\
\checkmark \\
\downarrow \\
\downarrow\end{array}$ \\
\hline
\end{tabular}

general area of specialization and education played a role in their understanding and interpretation of the diagrams. The depth of analysing the SMTs varied from one person to another, each individual had his/her skills, and they looked at the data on SMTs and VSM perceived them differently. This may have influenced their ratings and feedback in the study.

In this study, it was noted that the participants' familiarity with the HVI system and their role in a specific part of the patient journey is significant. For instance, in general, nurses are integrated caregivers partly or fully involved in all stages of the patient journey. However, PARs and physicians are more concentrated on their confined tasks. This situation potentially has an impact on the types of wastes they notice in the system. Although the diagrams presented the end-to-end patient journey, participants' familiarity with the particular step and process affected their waste identification ability. On the other hand, exposing stakeholders with SMTs made them more aware of the overall system, appreciate other roles, and see the effect and dependency of their tasks on other stakeholders. For example, during the observation, when PARs and HUCs evaluated the diagrams, they noticed some similarities between their activities. They also pointed out that appropriate coordination between them would improve the clinic's overall performance.

During the interviews, participants noted that external factors might also affect the system and contribute to waste generation. Expanding the system boundaries by including other departments, such as the call centre that handles booking patient appointments on the phone, or referrals from other clinical units, such as internal medicine, may help the waste identification process. Further, expanding the scope of SMTs by involving higher layers, such as patients, management, financial counsellor, and insurance companies, may give an enhanced picture of the system from different dimensions to understand system behaviour under different circumstances and recognize more wastes that could affect the overall system. As noted in the literature, lean considers both social and technical aspects in systems. ${ }^{34}$ Therefore, developing and implementing lean along with VSM and SMTs may help facilitate a gradual cultural and behavioural change.

While the results provided significant insights on SMTs and their contribution towards waste identification, the findings should be considered with limitations. For instance, this study was conducted in an outpatient clinic with a limited number of stakeholders; therefore, the findings' generalizability to other healthcare settings may be limited. It may also be expected that having more participants may have enhanced the discussion and strengthen the findings for validation and further statistical analysis. While this can be identified as a limitation, both qualitative and quantitative results derived in this study can be claimed to serve as a reliable indicator of an accomplishment that can be done within the timeframe of this study.

\section{Conclusions}

This study evaluated the usability and utility of SMTs in waste identification efforts in lean, along with the VSM. While the SMTs can be used in conjunction with VSM, they can also be used as stand-alone diagrams during lean activities, such as kaizen meetings, to enhance stakeholders' understanding of system behaviour and their engagement in system-wide waste identification efforts. Future research may consider applying SMTs in lean efforts in various healthcare settings to obtain further results for validation purposes. Researchers can also assess the training needs and resource intensiveness of SMTs compared to other waste identification tools and methods. 


\section{Ethics and consent}

The ethics approval was provided by the Institutional Review Board of Khalifa University of Science and Technology (Protocol No: H18-030). The written informed consent was obtained from study participants.

\section{Acknowledgments}

This publication is supported by the Khalifa University of Science and Technology under Award No. RCII-2019-002, Center for Digital Supply Chain and Operations Management, and Cleveland Clinic Abu Dhabi. The authors would like to thank all hospital staff who voluntarily participated in this study at the Heart and Vascular Institute at the Cleveland Clinic Abu Dhabi, UAE.

\section{Author Contributions}

All authors contributed to data analysis, drafting or revising the article, have agreed on the journal to which the article will be submitted, gave final approval of the version to be published, and agree to be accountable for all aspects of the work.

\section{Disclosure}

The authors declared no potential conflicts of interest with respect to the authorship and/or publication of this article. The part of background section of this paper was presented at the IEEE International Conference on Industrial Engineering and Engineering Management (IEEM) as a poster presentation with interim findings. The poster's paper was published in the proceeding of the 2019 IEEE International Conference on Industrial Engineering and Engineering Management (IEEM): doi: 10.1109/ IEEM44572.2019.8978929.

\section{References}

1. Gao T, Gurd B. Organizational issues for the lean success in China: exploring a change strategy for lean success. BMC Health Serv Res. 2019;19(1):66. doi:10.1186/s12913-019-3907-6

2. Improta G, Romano M, Di Cicco MV, et al. Lean thinking to improve emergency department throughput at AORN Cardarelli hospital. BMC Health Serv Res. 2018;18(1):914. doi:10.1186/s12913-018-3654-0

3. D'Andreamatteo A, Ianni L, Lega F, Sargiacomo M. Lean in healthcare: a comprehensive review. Health Policy Amst Neth. 2015;119 (9):1197-1209. doi:10.1016/j.healthpol.2015.02.002

4. Radnor Z, Walley P. Learning to walk before we try to run: adapting lean for the public sector. Public Money Manag. 2008;28(1):13-20.

5. Ricciardi C, Balato G, Romano M, Santalucia I, Cesarelli M, Improta G. Fast track surgery for knee replacement surgery: a lean six sigma approach. TQM J. 2020;32(3):461-474. doi:10.1108/TQM-06-2019-0159

6. Improta G, Ricciardi C, Borrelli A, D'alessandro A, Verdoliva C, Cesarelli $\mathrm{M}$. The application of six sigma to reduce the pre-operative length of hospital stay at the hospital Antonio Cardarelli. Int J Lean Six Sigma. 2019;11(3):555-576. doi:10.1108/IJLSS-02-2019-0014
7. Ricciardi C, Fiorillo A, Valente AS, et al. Lean Six Sigma approach to reduce LOS through a diagnostic-therapeutic-assistance path at A. O.R.N. A. Cardarelli. TQM J. 2019;31(5):657-672. doi:10.1108/ TQM-02-2019-0065

8. Kaltenbrunner M, Bengtsson L, Mathiassen SE, Högberg H, Engström M. Staff perception of Lean, care-giving, thriving and exhaustion: a longitudinal study in primary care. BMC Health Serv Res. 2019;19(1):652. doi:10.1186/s12913-019-4502-6

9. Mazzocato P, Holden RJ, Brommels M, et al. How does lean work in emergency care? A case study of a lean-inspired intervention at the Astrid Lindgren Children's hospital, Stockholm, Sweden. BMC Health Serv Res. 2012;12(1):28. doi:10.1186/1472-6963-12-28

10. Improta G, Balato G, Ricciardi C, et al. Lean Six Sigma in healthcare: fast track surgery for patients undergoing prosthetic hip replacement surgery. TQM J. 2019;31(4):526-540. doi:10.1108/ TQM-10-2018-0142

11. Daultani Y, Chaudhuri A, Kumar SA. Decade of lean in healthcare: current state and future directions: glob bus rev [Internet]. December 2, 2015 [cited April 2, 2020]. Available from: https://journals.sage pub.com/doi/10.1177/0972150915604520.

12. Ōhno T. Toyota Production System: Beyond Large-Scale Production/ Taiichi Ohno; Foreword by Norman Bodek. Cambridge, Massachusetts: Productivity Press; 1988.

13. Sibbald SL, Singer PA, Upshur R, Martin DK. Priority setting: what constitutes success? A conceptual framework for successful priority setting. BMC Health Serv Res. 2009;9:1-12. doi:10.1186/1472-69639-43

14. Ramaswamy R, Rothschild C, Alabi F, Wachira E, Muigai F, Pearson N. Using value stream mapping to improve quality of care in low-resource facility settings. Int J Qual Health Care. 2017;29 (7):961-965. doi:10.1093/intqhe/mzx142

15. Dickson EW, Singh S, Cheung DS, Wyatt CC, Nugent AS. Application of lean manufacturing techniques in the emergency department. J Emerg Med. 2009;37(2):177-182. doi:10.1016/j. jemermed.2007.11.108

16. Pinto CF, Coelho SM, Calado RD, Silva MB. Access improvement using lean healthcare for radiation treatment in a public hospital. IFAC Proc Vol. 2013;46(24):247-253. doi:10.3182/20130911-3-BR3021.00048

17. Bhat S, Gijo EV, Jnanesh NA. Application of Lean Six Sigma methodology in the registration process of a hospital. Int $J$ Product Perform Manag. 2014;63(5):613-643. doi:10.1108/IJPPM-11-20130191

18. Chiarini A. Waste savings in patient transportation inside large hospitals using lean thinking tools and logistic solutions. Leadersh Health Serv. 2013;26(4):356-367. doi:10.1108/LHS-052012-0013

19. Mazur LM, Chen SJ. Understanding and reducing the medication delivery waste via systems mapping and analysis. Health Care Manag Sci. 2008;11(1):55-65. doi:10.1007/s10729-007-9024-9

20. Henrique DB, Rentes AF, Filho MG, Esposto KF. A new value stream mapping approach for healthcare environments. Prod Plan Control. 2015;27(1):24-48. doi:10.1080/09537287.2015.1051159

21. Beuscart-Zéphir M-C, Pelayo S, Anceaux F, Maxwell D, Guerlinger S. Cognitive analysis of physicians and nurses cooperation in the medication ordering and administration process. Int $J$ Med Inf. 2007;76(Suppl 1):S65-77. doi:10.1016/j.ijmedinf.2006.05.022

22. Jun GT Design for patient safety: a systematic evaluation of process modelling approaches for healthcare system safety improvement [Ph.D. Thesis]. Cambridge: Cambridge University; 2007.

23. Simsekler MCE, Card AJ, Ward JR, Clarkson PJ. Trust-level risk identification guidance in the NHS East of England. Int $J$ Risk Saf Med. 2015;27(2):67-76. doi:10.3233/JRS-150651

24. Edwards N. Can quality improvement be used to change the wider healthcare system? Qual Saf Health Care. 2005;14(2):75. doi:10.1136/qshc.2005.013748 
25. Trebble TM, Hansi N, Hydes T, Smith MA, Baker M. Process mapping the patient journey: an introduction. BMJ. 2010;341: c4078. doi:10.1136/bmj.c4078

26. Clarkson PJ, Ward JR, Buckle P, Berman J. Prospective hazard analysis toolkit. Cambridge: University of Cambridge; 2010:Report No.: 978-0-9545243-4-0.

27. Ward J, Clarkson J, Buckle P, Berman J, Lim R, Jun T Prospective hazard analysis: tailoring prospective methods to a healthcare context. 2010

28. Jun GT, Ward J, Clarkson PJ. Systems modelling approaches to the design of safe healthcare delivery: ease of use and usefulness perceived by healthcare workers. Ergonomics. 2010;53(7):829-847. doi:10.1080/00140139.2010.489653

29. AlKaabi M, Simsekler MCE, Jayaraman R, Demirli K, Tuzcu EM. A review on the implementation of system modelling techniques in lean healthcare applications. In: 2019 IEEE International Conference on Industrial Engineering and Engineering Management (IEEM); 2019:1578-1582.
30. Jun GT, Ward J, Morris Z, Clarkson J. Health care process modelling: which method when? Int J Qual Health Care. 2009;21(3):214-224. doi:10.1093/intqhe/mzp016

31. Colligan L, Anderson JE, Potts HW, Berman J. Does the process map influence the outcome of quality improvement work? A comparison of a sequential flow diagram and a hierarchical task analysis diagram. BMC Health Serv Res. 2010;10(1):7. doi:10.1186/1472-6963-10-7

32. Simsekler MCE, Kaya GK, Ward JR, Clarkson PJ. Evaluating inputs of failure modes and effects analysis in identifying patient safety risks. Int J Health Care Qual Assur. 2019;32(1):191-207. doi:10.11 08/IJHCQA-12-2017-0233

33. Simsekler MCE, Ward JR, Clarkson PJ. Evaluation of system mapping approaches in identifying patient safety risks. Int J Qual Health Care. 2018;30(3):227-233. doi:10.1093/intqhe/mzx176

34. Burgess N, Radnor Z. Evaluating Lean in healthcare. Int J Health Care Qual Assur. 2013;26(3):220-235. doi:10.1108/0952686131 1311418
Risk Management and Healthcare Policy

\section{Publish your work in this journal}

Risk Management and Healthcare Policy is an international, peerreviewed, open access journal focusing on all aspects of public health, policy, and preventative measures to promote good health and improve morbidity and mortality in the population. The journa welcomes submitted papers covering original research, basic science, clinical \& epidemiological studies, reviews and evaluations,

\section{Dovepress}

guidelines, expert opinion and commentary, case reports and extended reports. The manuscript management system is completely online and includes a very quick and fair peer-review system, which is all easy to use. Visit http://www.dovepress.com/testimonials.php to read real quotes from published authors. 